\title{
Antitumor activity of celecoxib, a selective cyclooxygenase-2 inhibitor, in medullary thyroid carcinoma
}

\author{
QIANG ZHANG, XIANYING MENG, GUIBIN ZHENG, GUANG CHEN, \\ RENZHU PANG, TEBO HUA and SHUAI YANG
}

\author{
Department of Thyroid Surgery, First Hospital, Jilin University, Changchun, Jilin 130021, P.R. China
}

Received July 10, 2013; Accepted December 4, 2013

DOI: $10.3892 / \mathrm{mmr} .2013 .1869$

\begin{abstract}
The purpose of this study was to investigate the mechanisms of the antitumor effect of celecoxib (CXB) in the treatment of human medullary thyroid carcinoma (MTC). Human MTC TT cells were cultured with different concentrations $(0,20,40,60 \mu \mathrm{mol} / \mathrm{l})$ of CXB following $0-72 \mathrm{~h}$ in vitro. An MTT (3-[4,5-dimethylthiazol-2-yl]-2,5-diphenyltetrazolium bromide) assay was used to determine the growth inhibition of MTC in vitro. Flow cytometry was performed to analyze the cell cycle of TT cells. Levels of prostaglandin E2 (PGE2) were measured by enzyme-linked immunosorbent assay (ELISA) method. The expression profile of cyclooxygenase-2 (COX-2) and vascular endothelial growth factor (VEGF) was measured by western blot analysis. In the present study, it was identified that CXB inhibited TT cell proliferation and induced apoptosis in a dose- and time-dependent manner. The cell cycle was arrested at G0/G1 and the percentage of cells in $\mathrm{S}$ phase was markedly decreased. The expression levels of PGE2 were inhibited by CXB. CXB effectively downregulated the expression of COX-2 and VEGF in a doseand time-dependent manner. These data demonstrated that CXB inhibited the proliferation of MTC TT cells in vitro and thus may be effective as an antitumor therapy for human MTC.
\end{abstract}

\section{Introduction}

Medullary thyroid carcinoma (MTC), as first described by Hazard et al in 1959, is a rare malignant tumor originating from parafollicular C cells of the thyroid (1). Medullary tumors are the third most common of all thyroid cancers and constitute $\sim 3-4 \%$ of all cases (2). The reported 10-year mortality rate for patients with MTC varies from 13.5-38\% $(3,4)$. Furthermore, patients with distant MTC that are not surgically resectable or

Correspondence to: Professor Xianying Meng, Department of Thyroid Surgery, First Hospital, Jilin University, 71 Xinmin Street, Changchun, Jilin 130021, P.R. China

E-mail: xianying588@126.com

Key words: thyroid medullary carcinoma, cyclooxygenase-2, celecoxib, antitumor do not concentrate radioactive iodine ( $\mathrm{RAI}^{131}$ ), have worse prognoses. Chemotherapy has produced only occasional objective responses, which are usually of short duration $(5,6)$. Therefore, it is a necessity that novel therapeutic strategies for thyroid cancer patients that are refractory to standard therapies are examined.

Overexpression of cyclooxygenase-2 (COX-2) has been demonstrated in various types of tumor, including colon cancer (7), hepatocellular carcinoma (8) and gastric cancer (9). In addition, previous studies revealed that the expression of COX-2 mRNA and protein levels are increased in thyroid cancer tissue compared with non-neoplastic and benign thyroid tissues $(10,11)$. COX-2 is linked to numerous tumor-promoting effects, including tumor growth and metastasis, stimulation of invasion and angiogenesis $(12,13)$, enhancing drug resistance (14), and inhibiting apoptosis and immune surveillance (8). These studies imply that COX-2 may be important in carcinogenesis, which makes this enzyme, and the agents that act to inhibit its activity and expression, important targets in cancer therapeutics $(15,16)$.

Celecoxib (CXB), as a selective COX-2 inhibitor, has been widely marketed as an anti-inflammatory drug, being favourable for its improved safety and lower toxicity, compared with other nonsteroidal anti-inflammatory drugs (NSAIDs). It exerts potent anticancer effects in various tumor types, including colorectal, breast and lung cancers (17-19). However, there are limited data available on the antitumor activity of CXB in thyroid carcinoma. In this study, we investigated the effect of CXB on the cell cycle of human MTC TT cells and the possible mechanism underlying this effect, by examining the expression levels of vascular endothelial growth factor (VEGF) and COX-2.

\section{Materials and methods}

Reagents. CXB was obtained from Pfizer (New York, NY, USA). Stock solutions of $1 \mathrm{mM}$ CXB (Sigma-Aldrich, St. Louis, MO, USA) were dissolved in dimethyl sulfoxide (DMSO; Sigma-Aldrich), stored at $-20^{\circ} \mathrm{C}$, and diluted in a fresh medium immediately prior to use. For western blot analysis, the following antibodies were used; rabbit monoclonal antiCOX-2 and anti-VEGF (Cell Signaling Technology, Beverly, MA, USA), mouse monoclonal anti- $\beta$-Actin (Sigma-Aldrich) and horseradish peroxidase-conjugated goat anti-rabbit IgG (Santa Cruz Biotechnology, Santa Cruz, CA, USA). DMSO and 3-(4,5-dimethylthiazol-2-yl)-2,5-diphenyltetrazolium bromide (MTT) was obtained from Sigma-Aldrich and MTT 
was prepared by dissolving $1 \mathrm{mg}$ of each compound in $1 \mathrm{ml}$ of phosphate-buffered saline (PBS; pH 7.2). All other reagents were obtained from Sigma-Aldrich unless otherwise noted.

Cell culture. Human MTC cell line TT was obtained from the Cell Bank of the Chinese Academy of Sciences (Beijing, China) and were grown in RPMI-1640 medium (Invitrogen Life Technologies, Carlsbad, CA, USA) supplemented with $10 \%$ fetal bovine serum (FBS), $100 \mathrm{M}$ of nonessential amino acids and $100 \mathrm{mM}$ of L-glutamine (Invitrogen Life Technologies) at $37^{\circ} \mathrm{C}$ in a $5 \% \mathrm{CO}_{2}$ atmosphere and at $95 \%$ humidity. Once the cells achieved $70-80 \%$ confluence, they were washed, $2.5 \%$ trypsinized and replated. The growth medium was replaced with RPMI-1640 medium containing $5 \% \mathrm{FBS}$, as noted for individual experiments for $24 \mathrm{~h}$, and this medium was aspirated and replaced with fresh RPMI-1640 medium with the same FBS.

Cell viability analysis. MTT assay was used to determine the effect of CXB on the proliferation of TT cells. TT cells were incubated at a concentration of $5 \times 10^{3}$ cell/well in a 96 -well plate, and grown at $37^{\circ} \mathrm{C}$, in a $5 \% \mathrm{CO}_{2}$ incubator until cell adherence was evident. Following an overnight incubation in fresh RPMI-1640 medium containing 0.5\% FBS, the cells on the culture plate were divided into groups on the basis of parallel lines, with each group having four wells per line. After the $24 \mathrm{~h}$ attachment period, cells were treated with the indicated concentration of $(20,40,60 \mu \mathrm{mol} / \mathrm{l}) \mathrm{CXB}$. MTT $(20 \mu \mathrm{l} ; 5 \mathrm{mg} / \mathrm{ml})$ was added and the cells were incubated for another $4 \mathrm{~h}$ at the end of the treatment, $200 \mu \mathrm{l}$ of DMSO was added to each well following removal of the supernatant. Following shaking of the plate for 5-10 min, cell viability was obtained in the shaking board by measuring the absorbance at $490 \mathrm{~nm}$ wavelength by an enzyme-labeling instrument (ELX800, BioTek Instruments, Inc., Winooski, VT, USA). This assay was performed in triplicate. The inhibition rate was calculated according to the following formula (20); Inhibition rate $(\%)=[1-($ average absorbance of experimental group/average absorbance of blank control group)] x 100\%.

Apoptosis analysis. Cells were cultured in six-well plates in RPMI-1640 medium with 10\% FBS medium and were treated with different concentrations of CXB $(20,40,60 \mu \mathrm{mol} / \mathrm{l})$ for 24, 48 and $72 \mathrm{~h}$. The cover slips were washed three times with PBS and single cell suspensions were fixed in 1\% PBS. Cells were stained with $100 \mu \mathrm{g} / \mathrm{ml}$ acridine orange (AO) and $100 \mu \mathrm{g} / \mathrm{ml}$ ethidium bromide (EB) for $1 \mathrm{~min}$. Then, cells were observed under a fluorescence microscope. At least 200 cells were counted and the percentage of apoptotic cells was determined. Triplicates were performed in all experiments and experiments were performed on three occasions.

Cell cycle analysis. TT cells were treated with CXB for $24 \mathrm{~h}$ in RPMI-1640 medium containing 5\% FBS. All cells were collected, and $1 \times 10^{6}$ cells were centrifuged, resuspended in icecold $70 \%$ ethanol, and stored at $-20^{\circ} \mathrm{C}$ until analysis. Washed cells were stained by $0.1 \%$ Triton X-100 in PBS with $50 \mu \mathrm{g} /$ $\mathrm{ml}$ propidium iodide (PI; Sigma-Aldrich) and $1 \mathrm{mg} / \mathrm{ml} \mathrm{RNase}$ A (Invitrogen Life Technologies), and incubated at $37^{\circ} \mathrm{C}$ for $30 \mathrm{~min}$ in the dark. Samples of cells were then analyzed for DNA content by FACScan flow cytometry (Beckman Coulter, Miami, FL, USA), and cell cycle phase distributions were analyzed with the Cell Quest acquisition software (BD Biosciences, Bedford, MA, USA). Duplicates were performed in all experiments and the experiments were performed on three occasions.

Determination of prostaglandin E2 (PGE2) synthesis by enzyme-linked immunosorbent assay (ELISA). PGE2 synthesis was determined as previously described (21). In brief, TT cells were grown in 12-well plates overnight. The culture media of the cells were changed to new RPMI-1640 medium, 30 min prior to harvesting of the culture media, which were then centrifuged to remove cell debris. Cell-free culture media were collected at indicated times, then PGE2 levels were determined by competitive ELISA as described using the kit manufacturer (Cayman Chemical, Ann Arbor, MI, USA) by an ELISA reader ( $\mu$ Quant; BioTek Instruments, Inc.).

Western blotting analysis. Cells were seeded in six-well plates in RPMI-1640 medium containing 10\% FBS medium and were treated with different concentrations of CXB $(0,20,40$, $60 \mu \mathrm{mol} / \mathrm{l})$ for $48 \mathrm{~h}$. The cells were extracted with lysis buffer containing protease inhibitors (Sigma, St. Louis, MO, USA). Protein concentration was determined by bicinchoninic acid assay with bovine serum albumin (Sigma) as the standard. Western blotting was performed. Briefly, an equal amount of total cell lysate $(50 \mu \mathrm{g})$ was solubilized in sample buffer and boiled for $5 \mathrm{~min}$. This lysate $(25 \mu \mathrm{l})$ was then electrophoresed on a $8 \%$ SDS-PAGE gel and then the proteins were transferred to polyvinylidene difluoride membranes (Millipore, Billerica, MA, USA) by transfer buffer at $400 \mathrm{~mA}$ for $1 \mathrm{~h}$. Non-specific binding was blocked with 5\% skimmed milk powder for $1 \mathrm{~h}$ at room temperature. Membranes were incubated with the primary antibody overnight at $4^{\circ} \mathrm{C}$. The following primary antibodies were used: a polyclonal rabbit anti-human VEGF (dilution, 1:10,000; Santa Cruz Biotechnology, Inc.), rabbit anti-human COX-2 antibody (dilution, 1:1,000; Santa Cruz Biotechnology, Inc.). After washing three times with TBS-T solution and incubation of horseradish peroxidase-conjugated goat anti-rabbit $\mathrm{IgG}$ as the secondary antibody (dilution, 1:5,000; Santa Cruz Biotechnology, Inc.) for $1 \mathrm{~h}$ at room temperature, bands were visualized with the enhanced chemiluminescence system (GE Healthcare, Little Chalfont Bucks, Buckinghamshire, UK). Following this, membranes were re-blotted with anti- $\beta$-actin antibody for normalization and equal protein loading.

Statistical analysis. All the statistical analysis was performed by Graphpad Prism 5.0 software (GraphPad Software, San Diego, CA, USA). Data are presented using the mean \pm SD. The statistical significance was determined by using one-way analysis of variance (ANOVA) and Student's t-test. $P<0.05$ was considered to indicate a statistically significant result.

\section{Results}

Celecoxib inhibits the proliferation of MTC cells in vitro. To investigate whether CXB inhibited thyroid cancer cell proliferation, TT cells derived from poorly differentiated human medullary carcinoma cells, were treated with CXB at $20-60 \mu \mathrm{mol} / 1$ concentrations for 24,48 and $72 \mathrm{~h}$. The 


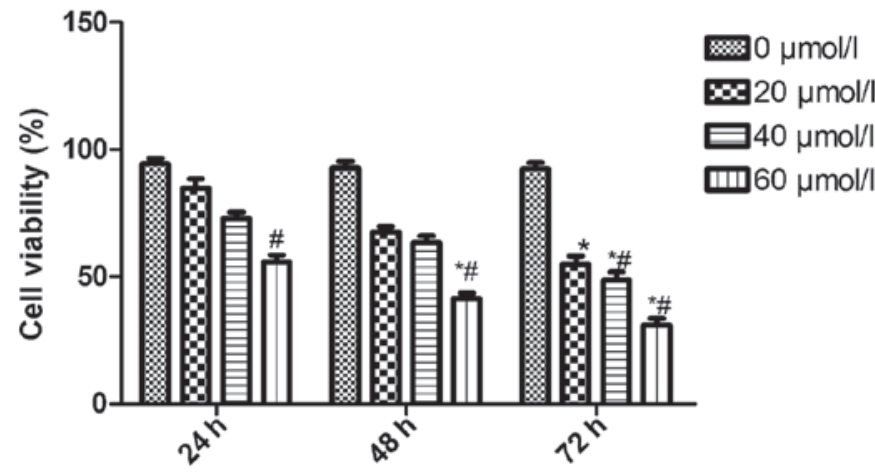

Figure 1. Growth inhibitory effects of CXB in TT cells. Cell viability was determined by the MTT method. This assay was performed in triplicate. Dose- and time-dependent inhibition of cell growth was observed after 24, 48 and $72 \mathrm{~h}(\mathrm{P}<0.05$, ANOVA analysis $) .{ }^{*} \mathrm{P}<0.05$ vs. $24 \mathrm{~h} ;{ }^{~} \mathrm{P}<0.05$ vs. $20 \mu \mathrm{mol} / 1$ CXB. CXB, celecoxib; MTT, 3-(4,5-dimethylthiazol-2-yl)-2,5diphenyltetrazolium bromide.

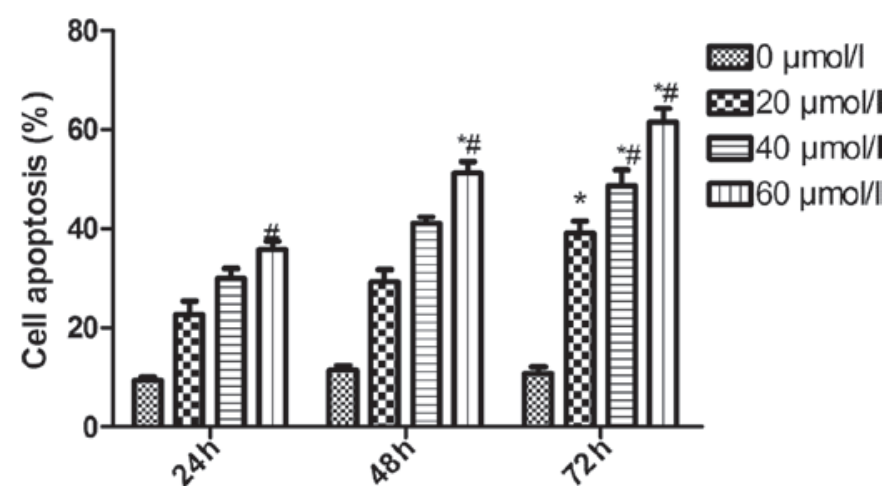

Figure 2. Effect of various concentrations of CXB on the apoptosis of TT cells in vitro. This assay was performed in triplicate. Dose- and time-dependent apoptosis of the cell was observed after 24,48 and $72 \mathrm{~h}\left({ }^{*} \mathrm{P}<0.05\right.$ vs. $24 \mathrm{~h}$; ${ }^{\#} \mathrm{P}<0.05$ vs. $\left.20 \mu \mathrm{mol} / 1 \mathrm{CXB}\right) . \mathrm{CXB}$, celecoxib.

antiproliferative effect of CXB on TT cells was examined using MTT assays. CXB was able to significantly inhibit the proliferation of TT cells in the high- and medium-dose groups. As demonstrated in Fig. 1, the inhibitory rates of CXB on cell growth were $45.54 \pm 3.21,57.82 \pm 4.53$ and $70.82 \pm 5.61 \%$ in TT cells, when the cells were treated with different doses $(20,40,60 \mu \mathrm{mol} / \mathrm{l})$ of CXB for $72 \mathrm{~h}$, respectively. As revealed in Fig. 1, CXB inhibited TT cell proliferation in a dose- and time-dependent manner.

CXB induces apoptosis in TT cells. To determine whether the cytotoxic effects of $\mathrm{CXB}$ were associated with apoptosis, AO staining was used on the TT cells following treatment with varying doses of $\mathrm{CXB}$. It was identified that $\mathrm{CXB}$ was able to induce apoptosis of the cells in a dose- and time-dependent manner (Fig. 2).

Effects of $C X B$ on the cell cycle distribution as examined by flow cytometry. To determine the effects of $\mathrm{CXB}$ treatment on TT cell cycle progression, flow cytometry was performed. In the CXB therapy groups, a significant decrease in the percentage of cells in the $\mathrm{S}$ phase and an increase of cells in the G0/G1 phase was observed. These effects occurred in a

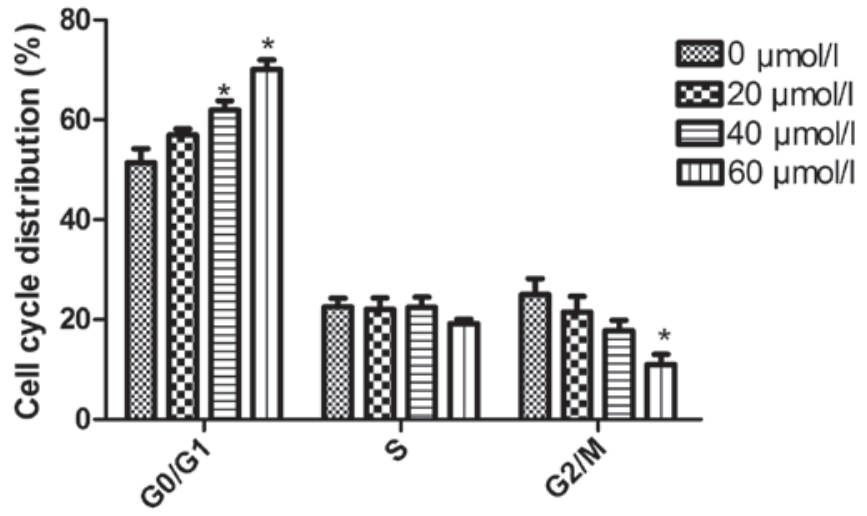

Figure 3. Effects of celecoxib on the cell cycle of TT cells as examined by flow cytometry. The cell cycle distributions in TT cells were determined by PI staining and flow cytometric analysis following treatment with $0-60 \mu \mathrm{mol} / 1 \mathrm{CXB}$ for $48 \mathrm{~h}$. The results are from three identical experiments $\left({ }^{*} \mathrm{P}<0.05\right.$ vs. control). $\mathrm{CXB}$, celecoxib; $\mathrm{PI}$, propidium iodide.

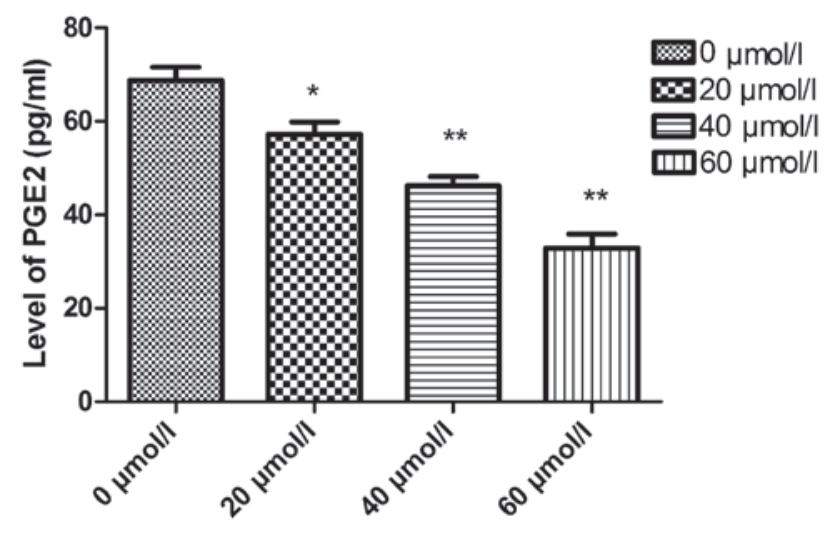

Figure 4. Effects of CXB on the PGE2 levels of TT cells by ELISA. PGE2 levels of TT cells were determined by ELISA following treatment with 0-60 $\mu \mathrm{mol} / 1 \mathrm{CXB}$ for $48 \mathrm{~h}$. This assay was performed in triplicate. Values represent the mean $\pm \mathrm{SD}$ and were determined using the Student's t-test. ${ }^{*} \mathrm{P}<0.05 ;{ }^{* *} \mathrm{P}<0.01$ vs. control. CXB, celecoxib; PGE2, prostaglandin E2; ELISA, enzyme-linked immunosorbent assay.

dose- and time-dependent manner. The results suggest that CXB is capable of inducing cell cycle arrest at the G0/G1 phase in TT cells (Fig. 3). In addition, the cells at the G2/M phase significantly decreased in the $60 \mu \mathrm{mol} / 1 \mathrm{CXB}$ group compared with that in the control group.

Effects of CXB on the PGE2 level of TT cells by ELISA. The PGE2 level of TT cells was determined by ELISA analysis. As shown in Fig. 4, the PGE2 levels of TT cells in the control group and in the 20-60 $\mu \mathrm{mol} / 1$ celecoxib groups were 76.12 \pm 8.91 , $57.24 \pm 6.55,43.25 \pm 5.02$ and $29.33 \pm 4.25 \mathrm{pg} / \mathrm{ml}$, respectively. PGE2 levels in the CXB therapy groups were significantly lower than that in the control group. Furthermore, the PGE2 expression level gradually decreased in a dose-dependent manner $(\mathrm{P}<0.01)$.

Effects of $C X B$ on $C O X-2$ and VEGF expression level in TT cells. To detect COX-2 and VEGF expression levels following CXB treatment at different doses, western blot analysis was performed. The results demonstrated that COX-2 and VEGF expression were highly expressed in normal TT 

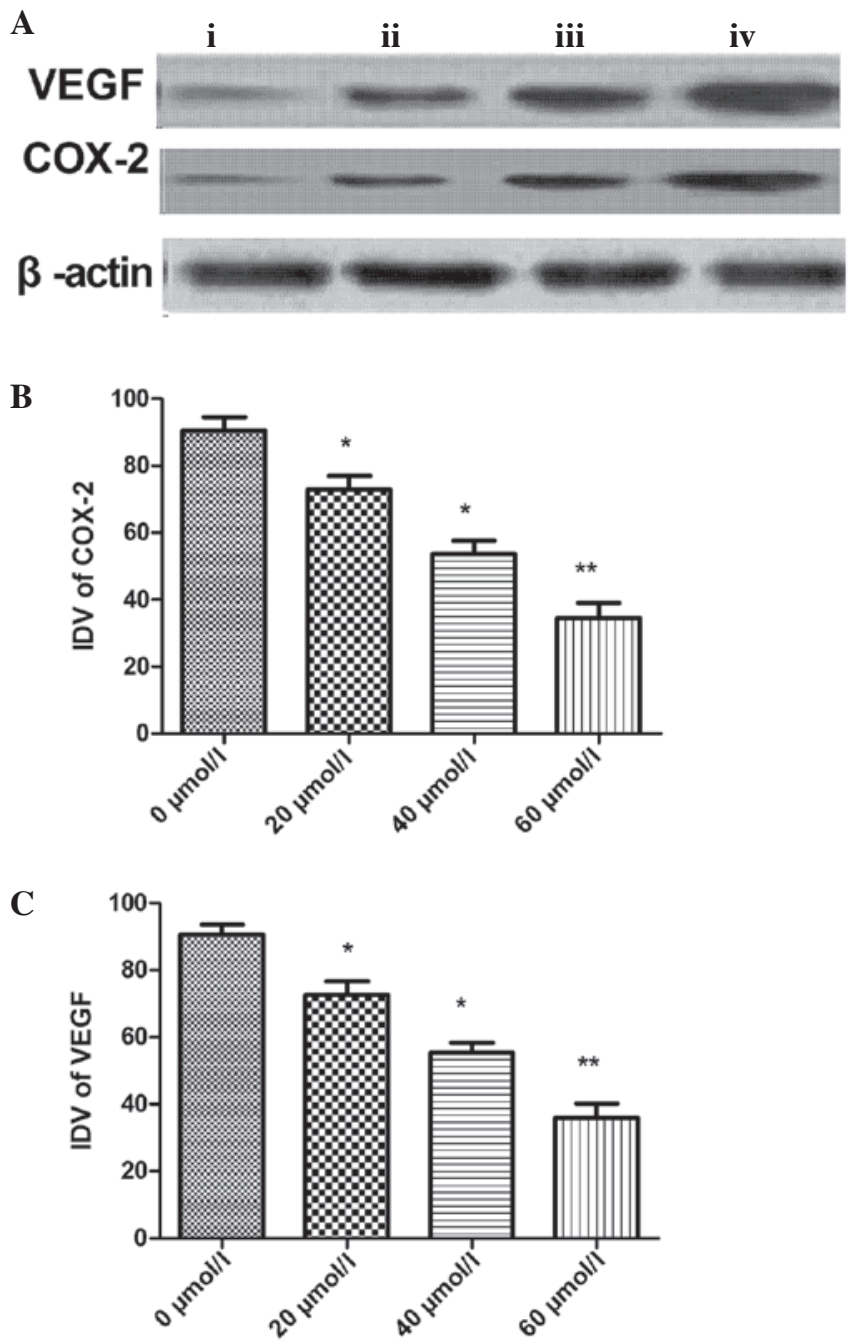

Figure 5. Effect of CXB on the expression of COX-2 and VEGF of TT cells by western blotting following treatment with $0-60 \mu \mathrm{mol} / 1 \mathrm{CXB}$ for $48 \mathrm{~h}$. (A) Western blot determined COX-2 and VEGF protein expression after CXB treatment at various concentrations. (i) $60 \mu \mathrm{mol} / 1 \mathrm{CXB}$; (ii) $40 \mu \mathrm{mol} / 1 \mathrm{CXB}$; (iii) $20 \mu \mathrm{mol} / 1 \mathrm{CXB}$; (iv) control. (B) Integrated density value (IDV) of COX-2. (C) Integrated density value (IDV) of VEGF. This assay was performed in triplicate. Values represent the mean $\pm \mathrm{SD}$ and were determined using the Student's t-test, ${ }^{\mathrm{P}}<0.05,{ }^{* *} \mathrm{P}<0.01$ vs. control. CXB, celecoxib; COX-2, cyclooxygenase-2; VEGF, vascular endothelial growth factor.

cells. Furthermore, as the CXB concentration increased, the expression of COX-2 and VEGF gradually decreased. As summarized in Fig. 5, the extent of COX-2 and VEGF expression in TT cells following CXB treatment significantly decreased in a dose-dependent manner.

\section{Discussion}

A number of epidemiological data, laboratory studies and clinical observations have demonstrated that NSAIDs are effective therapeutic strategies in the prevention and inhibition of digestive tract tumors, as external and internal treatments (17-19). CXB is a novel COX-2 selective inhibitor and is the only NSAID drug that has been approved by the FDA (Food and Drug Administration; December 1999) for adjuvant treatment of patients with familial adenomatous polyposis. This anti-inflammatory drug has potent antitumor activity in a wide variety of human tumor types, including colorectal, breast and lung cancers (17-19). The importance of $\mathrm{CXB}$ in the prevention and treatment of cancerous tumors has been attracting considerable attention in recent years, due to its selective and specific inhibition of COX-2 activity (22-24). The anticarcinogenic mechanisms of CXB include, inhibiting cell cycle progression, angiogenesis, apoptosis and suppressing tumor metastasis (25-27). Our data demonstrate that CXB inhibited the proliferation and induced apoptosis of TT cells in a dose- and time-dependent manner.

The enzyme COX-2 is known to be involved in multiple pathophysiological processes, including inflammation and tumorigenesis $(19,28)$. COX-2 is undetectable in the majority of normal, healthy tissues, yet it is commonly overexpressed in numerous malignant, premalignant and metastatic human cancer types, including thyroid. The key mediator of the enzyme's tumor stimulating effect is its downstream product, PGE2, which is often overexpressed with COX-2 in malignant tissues. PGE2 is important in tumor-promoting inflammation (29), and also promotes tumor cell proliferation, induces VEGF upregulation and inhibits tumor cell apoptosis, as well as immune function (30). A number of studies have identified that COX-2 is critical in carcinogenesis and cancer progression, as a result of its participation in tumor initiation, in encouraging metastatic spread, and also in promoting tumor maintenance and progression $(31,32)$. Thus, the selective inhibition of COX-2 activity is an important target for developing novel therapeutic strategies in the treatment of cancer. In the present study, our data indicate that $\mathrm{CXB}$ reduced cell viability and the expression of intracellular COX-2 and PGE2 in TT cells in a dose-dependent manner. Therefore, CXB was able to suppress expression of COX-2 to inhibit cell proliferation in cancer pathogenesis.

Through the formation of a microvascular network, the process of angiogenesis provides cancerous cells with a blood supply rich in oxygen and nutrients, and thus is a major attribute of tumorigenesis and tumor growth $(33,34)$. This process is stimulated by several key regulators, including IL-8 and VEGF. VEGF is regarded as the most important of all angiogenic molecules. Investigations have identified that stimulated VEGF binds to VEGF receptor 2 (VEGFR2) in tumors, contributing to the proliferation, migration and invasion of breast cancer cells. In numerous studies, VEGF overexpression has been documented in thyroid carcinomas and they were not able to discover a correlation between VEGF staining pattern and gender, age, tumor diameter and metastasis (35-37). Therefore, the selective inhibition of VEGF activity is important for the treatment of cancer. Furthermore, it has been demonstrated that CXB inhibits the COX enzymes, downregulates the level of PGE2 and reduces the production of VEGF in numerous tumor types $(38,39)$. In the present study, our result confirmed that $\mathrm{CXB}$ inhibits COX2 expression, downregulates the expression levels of PGE2 and decreases the production of VEGF, which are all effects that may explain the mechanisms that underlie CXB's antitumor activity.

In conclusion, celecoxib inhibited the proliferation of human MTC cell line in vitro. Of note, the inhibitory effect of $\mathrm{CXB}$ on the proliferation of human MTC in vitro was observed in a dose- and time-dependent manner. The cell cycle was arrested at G0/G1, and the percentage of cells in 
the $\mathrm{S}$ phase was markedly decreased. Furthermore, $\mathrm{CXB}$ was able to inhibit VEGF and COX-2 expression in vitro. These data demonstrated that CXB is effective as an antitumor therapeutic, however, further studies are required to clarify the detailed mechanisms underlying this effect.

\section{Acknowledgements}

The authors gratefully acknowledge the financial support provided by the Health Bureau of Jilin (2008Z017).

\section{References}

1. Hazard JB, Hawk WA and Crile G Jr: Medullary (solid) carcinoma of the thyroid; a clinicopathologic entity. J Clin Endocrinol Metab 19: 152-161, 1959.

2. Davies L and Welch HG: Increasing incidence of thyroid cancer in the United States, 1973-2002. JAMA 295: 2164-2167, 2006.

3. Girelli ME, Nacamulli D, Pelizzo MR, et al: Medullary thyroid carcinoma: clinical features and long-term follow-up of seventyeight patients treated between 1969 and 1986. Thyroid 8: 517-523, 1998.

4. Modigliani E, Cohen R, Campos JM, et al: Prognostic factors for survival and for biochemical cure in medullary thyroid carcinoma: results in 899 patients. The GETC Study Group. Groupe d'étude des tumeurs à calcitonine. Clin Endocrinol (Oxf) 48: 265-273, 1998.

5. Droz JP, Schlumberger M, Rougier P, et al: Chemotherapy in metastatic nonanaplastic thyroid cancer: experience at the Institut Gustave-Roussy. Tumori 76: 480-483, 1990.

6. O'Doherty MJ and Coakley AJ: Drug therapy alternatives in the treatment of thyroid cancer. Drugs 55: 801-812, 1998.

7. Soumaoro LT, Uetake H, Higuchi T, Takagi Y, Enomoto M and Sugihara K: Cyclooxygenase-2 expression: a significant prognostic indicator for patients with colorectal cancer. Clin Cancer Res 10: 8465-8471, 2004

8. Ogunwobi $\mathrm{OO}$ and Liu C: Hepatocyte growth factor upregulation promotes carcinogenesis and epithelial-mesenchyma transition in hepatocellular carcinoma via Akt and COX-2 pathways. Clin Exp Metastasis 28: 721-731, 2011.

9. Thiel A, Mrena J and Ristimäki A: Cyclooxygenase-2 and gastric cancer. Cancer Metastasis Rev 30: 387-395, 2011.

10. Saad MF, Ordonez NG, Rashid RK, et al: Medullary carcinoma of the thyroid. A study of the clinical features and prognostic factors in 161 patients. Medicine (Baltimore) 63: 319-342, 1984.

11. Pelizzo MR, Boschin IM, Bernante P, et al: Natural history, diagnosis, treatment and outcome of medullary thyroid cancer: 37 years experience on 157 patients. Eur J Surg Oncol 33 493-497, 2007

12. Chen WT, Hung WC, Kang WY, et al: Overexpression of cyclooxygenase-2 in urothelial carcinoma in conjunction with tumor-associated-macrophage infiltration, hypoxiainducible factor-1alpha expression, and tumor angiogenesis. APMIS 117 176-184, 2009.

13. Liu H, Xiao J, Yang Y, et al: COX-2 expression is correlated with VEGF-C, lymphangiogenesis and lymph node metastasis in human cervical cancer. Microvasc Res 82: 131-140, 2011.

14. Mehar A, Macanas-Pirard P, Mizokami A, Takahashi Y, Kass GE and Coley HM: The effects of cyclooxygenase- 2 expression in prostate cancer cells: modulation of response to cytotoxic agents J Pharmacol Exp Ther 324: 1181-1187, 2008.

15. Ghosh N, Chaki R, Mandal V, and Mandal SC: COX-2 as a target for cancer chemotherapy. Pharmacol Rep 62: 233-244, 2010

16. Hsu YL, Kuo YC, Kuo PL, Ng LT, Kuo YH and Lin CC: Apoptotic effects of extract from Antrodia camphorata fruiting bodies in human hepatocellular carcinoma cell lines. Cancer Lett 221: 77-89, 2005 .

17. Lou J, Fatima N, Xiao Z, et al: Proteomic profiling identifies cyclooxygenase-2-independent global proteomic changes by celecoxib in colorectal cancer cells. Cancer Epidemiol Biomarkers Prev 15: 1598-1606, 2006

18. Abou-Issa HM, Alshafie GA, Seibert K, Koki AT, Masferrer JL and Harris RE: Dose-response effects of the COX-2 inhibitor, celecoxib, on the chemoprevention of mammary carcinogenesis. Anticancer Res 21: 3425-3432, 2001.
19. Park W, Oh TY, Han JH and Pyo H: Antitumor enhancement of celecoxib, a selective Cyclooxygenase-2 inhibitor, in a Lewis lung carcinoma expressing Cyclooxygenase-2. J Exp Clin Cancer Res 27: 66, 2008

20. Dai ZJ, Gao J, Li ZF, et al: In vitro and in vivo antitumor activity of Scutellaria barbate extract on murine liver cancer. Molecules 16: 4389-4400, 2011.

21. Tai $\mathrm{MH}$, Weng $\mathrm{CH}$, Mon DP, et al: Ultraviolet $\mathrm{C}$ irradiation induces different expression of Cyclooxygenase 2 in NIH 3T3 cells and A431 cells: The roles of COX-2 are different in various cell lines. Int J Mol Sci 13: 4351-4366, 2012.

22. Jang TJ, Jung HG, Jung KH and O MK: Chemopreventive effect of celecoxib and expression of cyclooxygenase-1 and cyclooxygenase- 2 on chemically-induced rat mammary tumours. Int J Exp Pathol 83: 173-182, 2002.

23. Keller JJ and Giardiello FM: Chemoprevention strategies using NSAIDs and COX-2 inhibitors. Cancer Biol Ther 2 (4 Suppl 1): $1-29,2003$.

24. Hilmi I and Goh KL: Chemoprevention of colorectal cancer with nonsteroidal anti-inflammatory drugs. Chin J Dig Dis 7: 1-6, 2006.

25. Park SW, Kim HS, Hah JW, Jeong WJ, Kim KH and Sung MW: Celecoxib inhibits cell proliferation through the activation of ERK and p38 MAPK in head and neck squamous cell carcinoma cell lines. Anticancer Drugs 21: 823-830, 2010.

26. Fischer SM, Hawk ET and Lubet RA: Coxibs and other nonsteroidal anti-inflammatory drugs in animal models of cancer chemoprevention. Cancer Prev Res (Phila) 4: 1728-1735, 2011.

27. Sobolewski C, Cerella C, Dicato M and Diederich M: Cox-2 inhibitors induce early c-Myc downregulation and lead to expression of differentiation markers in leukemia cells. Cell Cycle 10: 2978-2993, 2011.

28. Müller-Decker K and Fürstenberger G: The cyclooxygenase2-mediated prostaglandin signaling is causally related to epithelial carcinogenesis. Mol Carcinog 46: 705-710, 2007.

29. Rasmuson A, Kock A, Fuskevåg OM, et al: Autocrine prostaglandin E2 signaling promotes tumor cell survival and proliferation in childhood neuroblastoma. PLoS One 7: e29331, 2012.

30. Pockaj BA, Basu GD, Pathangey LB, et al: Reduced T-cell and dendritic cell function is related to cyclooxygenase-2 overexpression and prostaglandin E2 secretion in patients with breast cancer. Ann Surg Oncol 11: 328-339, 2004.

31. Grösch S, Maier TJ, Schiffmann S and Geisslinger G: Cyclooxygenase-2 (COX-2)-independent anticarcinogenic effects of selective COX-2 inhibitors. J Natl Cancer Inst 98: 736-747, 2006.

32. Reddy BS, Hirose Y, Lubet R, et al: Chemoprevention of colon cancer by specific cyclooxygenase- 2 inhibitor, celecoxib, administered during different stages of carcinogenesis. Cancer Res 60 : 293-297, 2000

33. Rajput S and Mandal M: Antitumor promoting potential of selected phytochemicals derived from spices: a review. Eur J Cancer Prev 21: 205-215, 2012.

34. McNamara DA, Harmey J, Wang JH, Kay E, Walsh TN and Bouchier-Hayes DJ: Tamoxifen inhibits endothelial cell proliferation and attenuates VEGF-mediated angiogenesis and migration in vivo. Eur J Surg Oncol 27: 714-718, 2001.

35. Bozbora A, Erbil Y, Türe N, Barbaros U and Özarmagan S: Role of vascular endothelial growth factor in the prognosis of papillary thyroid cancer. The Endocrinologist 16: 168-171, 2003.

36. Bunone G, Vigneri P and Bongarzone I: Expression of angiogenesis stimulators and inhibitors in human thyroid tumors and correlation with clinical pathological features. Am J Pathol 155: 1967-1976, 1999.

37. Fenton C, Patel A, Dinauer C, et al: The expression of vascular endothelial growth factor and the type 1 vascular endothelial growth factor receptor correlate with the size of papillary thyroid carcinoma in children and young adults. Thyroid 10: 349-357, 2000.

38. Kirkpatrick K, Ogunkolade W, Elkak A, Bustin S, Jenkins P, Ghilchik $\mathrm{M}$ and Mokbel K: The mRNA expression of Cyclooxygenase-2 (COX-2) and vascular endothelial growth factor (VEGF) in human hreast cancer. Curr Med Res Opin 18: 237-241, 2002.

39. Wei D, Wang L, He Y, Xiong HQ, Abbruzzese JL and Xie K. Celecoxib inhibits vascular endothelial growth factor expression in and reduces angiogenesis and metastasis of human pancreatic cancer via suppression of Spl transcription factor activity. Cancer Res 64: 2030-2038, 2004. 